\title{
On the Cultivation of Cross-cultural Awareness in English Literary Teaching
}

\author{
Hanyue Zhang \\ College of Foreign Languages and Literature, Wuhan Donghu University, Wuhan Hubei, \\ 430212, China
}

Keywords: English literature, Education, Cross-cultural awareness.

\begin{abstract}
In the English teaching in China, the English literary education is paid more and more attention. In the current English literary education, it is urgent to promote students' cross-cultural awareness, which ask them to understand the background of a lot of English literatures, study the implication according to the background cultures and thus get the most realistic teaching effect to promote English teaching in China entering into higher level. This thesis elaborates the great significance to cultivate cross-cultural awareness in English literary education, analyzes the relation between English literary education and cultivation of cross-cultural awareness and proposes countermeasure to intensify cultivation of cross-cultural awareness during English literary education.
\end{abstract}

\section{Introduction}

Nowadays, human society has entered into a new period of diversified development. The global cultural system has broken inherent cultural thinking mode and introduced diversified and systematic thinking modes, which result in the collision and intersection of various kinds of cultures. It asks us to carefully inspect each national culture and custom to avoid cultural conflict. Literature can be regarded as the important crystal of national culture. Studying English literature can help to learn cultural connotations and values in western culture. Thus, applying cross-cultural awareness to advance English literary education is always the significant topic that deserves thorough exploration in teaching for English major. Cross-cultural awareness mainly refers to understanding other national cultural connotations under the premise of understanding and inheriting local culture. Under the shock of integration of world economy, the requirement to people's English competence keeps enhancing, asking English major graduates not only to speak fluent English but also to comprehensively and deep understand English-speaking country's culture. This results in more and more attention to the cultivation of cross-cultural awareness.

\section{Significance to Cultivate Cross-cultural Awareness in English Literary Education}

Cross-cultural awareness is the indispensable ability during globalization, and meanwhile an important goal in English literary teaching. As early as the middle of last century, Edward Hall, an American cultural scholar, firstly proposed the concept of cross-cultural communication and made it become the independent study field. The formation of cross-cultural awareness is of uncountable significance to the cultural communication all over the world. Cross-cultural awareness is not the simple addition of two or more culture symbols, but includes individual endogenous capacity, cultural difference, mental stress, etc. It has been a long time of each national education circle to pay attention to cross-cultural awareness. After the Second World War, America gradually introduced the education of cross-cultural awareness. In recent years, with the reflection of important value of cross-cultural communication, American researchers developed many evaluation tools one after another. For example, American International Education College established a whole set of evaluation mechanism, with the purpose to help receivers to know more about the real effect of cross-cultural communication. In this way, it could judge whether this person could take weighty responsibility in multi-culture group or dwell abroad, and what preparations have been done to enter into another cultural environment. Thus, cultivating cross-cultural awareness and communicative 
competence are the indispensable qualities for the new-generation undergraduates as well as the required course for students of English major. The giant change of English literary implication makes readers, especially cross-culture readers, pay more attention to the cultivation of cross-cultural awareness during reading, which also reflects the level of sensitivity, tolerance and flexibility to cultural difference. During the cultivation process, it would inevitably refer to the relation between native language cultural awareness and target-language cultural awareness, so as to form good cross-cultural awareness system. During the transition from native language cultural awareness to target-language cultural awareness, the accommodation of culture is very important. Certainly, in English literary education, when facing the mutual cross-culture intercommunity and difference of each English-speaking country, it needs also big sensitivity to avoid essentialism error.

\section{Relation Analysis between English Literary Teaching and Cultivation of Cross-cultural Awareness}

Firstly, cultivating the cross-cultural awareness is an important component in English literary teaching system. Literatures could always reflect the cultural essence of a country, with national spirit, cultural inheritance, customs, mental state, etc. Of course, English literatures also undertake the local conditions and customs of those countries with English as native language. Based on English literature teaching, it could help to grasp those national politics, economy, society, etc. which means when implementing English literary education, learners' cross-cultural awareness should be enhanced during everyday education activities such as reading, literature appreciation, etc. Secondly, cultivating cross-cultural awareness could help to promote teaching effect of English literatures. Cross-cultural awareness asks learners not only to initiatively study western cultures but also to comprehensively compare western cultures and local culture to find their similarity and difference, which could promote individual cultural sensitivity. As long as its cross-cultural awareness is improved, after going to appreciate and study the English literary education, learners would positively discover the customs in each country with English as the native language. At the same time, those undergraduates with rather strong cross-cultural awareness could combine their own culture, find the similarity and difference between other countries' culture and our national culture and make pointed references to assimilate essence of western culture and get rid of dregs. It is based on independent study and comparison study of learners to deepen understanding to English literatures, better promoting actual quality of English literature teaching in institutions of higher education and intensifying the effect of English literature teaching. Thirdly, English literature education has become the important channel to promote cross-cultural awareness. The culture can be fully revealed in literatures and one of the important literary values is the cultural contents contained in literature. For example, when a piece of literature mainly describing people explains the growth process of leading character, it would definitely explain the growth background which could reflect the politics, economy, culture, custom, thoughts and feelings, etc. of a country at some time. The personal character in literature could also reflect the bright feature of people in some age, and the personal character would reveal the economic development condition and social changes of that country at some time. As for the literature aspect, English literature could well promote cross-cultural awareness of young students.

\section{Countermeasure to Intensify the Cultivation of Cross-cultural Awareness in English Literature Teaching}

\section{To Show the Important Role of Class Teaching}

English literature teachers mainly play the role of guidance and enlightenment during class teaching. Thus during class teaching, teachers should fully use their own rights to positively guide students. For example, they should try their best to dig the containing culture in English literature books and teach to the undergraduates. At the same time, as for the contents with cultural connotations mentioned but 
not deeply studied in the English literature books, group discussion or question and answer mode can be used to inspire learners to actively explore, which could not only active learning atmosphere in class but also deepen students overall mastering to the cultural connotations in English literatures by their own active exploration. In addition, this can help to give the class back to students. Firstly, it needs to provide enough time for study, appreciating the appointed literature, and then ask each learner to talk about the cultural knowledge acquired from literatures in English. They should also tell their own understanding to this literature. Lastly, let them summarize the differences between Chinese and Western cultures. This rather open English literature teaching could not only promote students' taste to English literatures and English ability in oral expression but also upgrade their cross-cultural awareness by comparison of Chinese and Western cultures.

\section{To Play the Leading Role in Extracurricular Activities}

In institutions of higher education, if teachers want to cultivate students' cross-cultural awareness, it is not enough to only depend on the finite time in class and limited contents in books. They need to actively guide students to rationally make use of spare time to cultivate their own cross-cultural awareness. English literature teachers could make use of time in class to teach some experience for students to promote English literature level and deepen their understanding to western culture. What teachers recommend should be those classic works that could help students enhance their own cross-cultural awareness during reading. On this basis, English literature teachers could also encourage some excellent students to watch some classic English movies, listen to some English music pieces with English cultural connotations and guide them to write review to deepen their understanding. Of course, teachers could also make use of spare time to organize students to listen some speeches in the aspect of English literature, helping students to learn English-speaking countries' unique culture and profoundly experience the differences between Chinese and Western cultures.

\section{To Promote Exercise of Cultural Transference}

Nowadays, cultural transference has become one of the most important contents to cultivate students' cross-cultural awareness, which is of great influence to promote their cross-cultural awareness. During the whole process of enhancing learners' cross-cultural awareness, cultural transference is an indispensable important element. There are different cultures in different countries or regions. In order to let learners full understand each culture, it needs to form perfect communication channel among those cultures, generate an understandable medium for each other, consider problems with different cultural thinking modes of different nations and intensify their understanding and mastering to each literature. When cultivating the cross-cultural awareness, it needs to find the connections among each different culture and integrate them under the integration circumstance, analyzing the culture from different angles so as to adapt the requirements of the current age. It's worth noting that cultural transference belongs to subjective consciousness. Only if students start from their self-consciousness and more consciously go into the study of English culture can they get rid of the limitation of local culture from mentality and emotion and thus further realize promotion of cross-cultural awareness under multiple cultural backgrounds.

\section{To Introduce Multimedia Teaching Measure}

Considering the continuous progress of current technological developmental level and continuous development of higher educational business, there has been more and more advanced technologies applied to teaching. English literature teachers in college and university must rationally make use of new technologies to better teaching. Firstly, they could use such patterns as illustration in class teaching to make students more intuitively understand the involved contents in teaching materials and master English-speaking countries' customs. Secondly, teachers could also gather some relevant materials before class and help students to more quickly enter into the artistic conception created by literature and further promote their cross-cultural awareness. 


\section{To Promote Teachers Professional Competence and Quality}

English literature teachers have leading status in class teaching, whose role is to guide and enlighten the learners. Thus when helping students to form cross-cultural awareness, teachers should also devote themselves to promote their own professional competence and quality. The first is the promotion of professional competence. Professional competence mainly refers to the English literature competence that teachers have. If you want to let learners to be able to further and fully understand literature, it needs to ensure that teachers could deeply and fully understand this literature and be familiar with the social reality reflected by the work. Only by this could ensure teachers to correctly guide learners and help them gradually enter into its situation, appreciate its language and taste its charms. And then let them to systematically explore the involved cultural connotations in literatures. The second is the promotion of professional quality, which mainly refers that teaching method and idea of English literature teachers should advance with the times. They can not just repeat what the book says but to explain the contents of article from easier to deep and further explain the difficult parts so as to help learners to experience the differences between Chinese and Western cultures and promote their cross-cultural awareness.

\section{Conclusion}

To sum up, to actively cultivate learners' cross-cultural awareness in English literature teaching in the current institutions of higher education could not only promote learners' cross-cultural awareness to meet the development requirement under the new situation but also enhance English literature education in the current institutions of higher education to some extent. In order to better play the important role of cross-cultural awareness, teachers should actively guide students to adopt various ways to promote individual cross-cultural awareness and show the effect of English literature education as far as possible.

\section{References}

[1] Liu Yaqian, Brief Analysis of British and American Literature Teaching and Cultivation of Cross-cultural Awareness, academic journal of social sciences in Jiamusi University, 2011 (10).

[2] Wang Xiaodan, Cultivation of Cross-cultural Awareness of American Literature Teaching, Heilongjiang Researches on Higher Education, 2012 (3).

[3] Cheng Yan, Exploration to British and American Literature Study with Cultural Awareness, academic journal in Hunan Industry Polytechnic, 2012 (6).

[4] Wu Ting, Primary Exploration to Cultivation Strategies of Cross-cultural Awareness in English Teaching, Weekly Magazine for Examination, 2012 (7)

[5] Wang Xiaoming, Liu Jianying, Cultivation of Cross-cultural Awareness in British and American Literature Teaching, Technology Wind, 2013 (12) 